\title{
Measurement and Characteristic Analysis of Electromagnetic Disturbance of Coal Mine Fan Converter
}

\author{
Zhonghua Xin $\mathbb{D}^{1},{ }^{1,2}$ Xiaodong Zhang $\mathbb{D}^{1,3}$ Shuqian Yu $\mathbb{D}^{1},{ }^{1}$ Huijuan Wang $\mathbb{D}^{1}$ \\ Xiaoqian Jia $\mathbb{D},{ }^{1}$ and Yuling Ma $\mathbb{D}^{3}$ \\ ${ }^{1}$ School of Electrical Engineering, Beijing Jiaotong University, Beijing 100044, China \\ ${ }^{2}$ EMC Lab of the CCTEG China Coal Research Institute, Beijing 100013, China \\ ${ }^{3}$ Cangzhou Jiaotong College, Huanghua, Hebei 061199, China
}

Correspondence should be addressed to Xiaodong Zhang; xdzhang@bjtu.edu.cn

Received 29 April 2021; Accepted 23 July 2021; Published 5 August 2021

Academic Editor: Giuseppe Castaldi

Copyright ( 12021 Zhonghua Xin et al. This is an open access article distributed under the Creative Commons Attribution License, which permits unrestricted use, distribution, and reproduction in any medium, provided the original work is properly cited.

With the extensive use of converters in high-power ventilator, shearer, road header, conveyor, hoist, and other coal mine equipment, the electromagnetic disturbance problem of the converter is worthy of attention. In this paper, the field measurement and statistical method are used to analyze the radiation interference characteristics of frequency converter. Then, a typical fan converter is taken as an example, and the electromagnetic disturbance of the converter is tested in four key positions and two working frequencies, respectively. Multiple sets of data and spectrum are obtained by using a spectrum analyzer and other instruments, and the dominant frequency characteristic parameters of the converter are analyzed emphatically. The small sample data adopts the Shapiro-Wilk test, and the $80 \% / 80 \%$ rule was used for statistical analysis. Finally, we got five common frequencies of electromagnetic interference generated by the converter (electric field $\mathrm{dB} \mu \mathrm{V} / \mathrm{m}$ ). The $\mathrm{CH}_{4}$ sensor and other sensors work near these five dominant frequencies, which may affect the normal operation of the sensor and cause alarm. The test and analysis method proposed in this paper can be used to obtain the characteristic parameters of the converter electromagnetic disturbance, which can be used as a reference for the design of the immunity of sensors or control instruments.

\section{Introduction}

In recent years, the improvement of the technology of coal mine equipment makes the electrical equipment develop towards diversification, large scale, high voltage, and high power [1]. Converters and other nonlinear electrical equipment are widely used in high-power ventilator, shearer, road header, conveyor, hoist, and other electrical equipment. These high-power pieces of equipment may produce many types of electromagnetic disturbance. The electromagnetic disturbance is aggravated by the dense distribution of various metal pipelines in the narrow closed space such as underground roadway, and the electromagnetic environment of underground working space becomes more complex [2]. The electromagnetic environment in coal mine has become a key research problem. Coal mine safety monitoring system is one of several major systems that must be available in coal mine safety production, which is used to monitor various environmental parameters and equipment in coal mines and give an alarm when finding abnormal. It is also an important source of data analysis of coal mine safety technology, where the $\mathrm{CH}_{4}$ sensor is particularly important [3].

Since the 1970s, many researchers have done a lot of work in the measurement and statistical analysis of electromagnetic disturbance of electrical equipment. Measurement results show that switching operation may produce a series of transient pulses, causing conducted emissions. Disturbances have large impacts on the monitoring circuitry of the mine equipment, causing the mine monitoring system to frequently record erroneous data and omit information $[4,5]$. The transmission characteristics of electromagnetic wave in coal mine roadway and cable $[6,7]$ and the electromagnetic environment of coal mining face [8] are 
proposed. Wang Minyan [9] simply analyzed the harmonic pollution and electromagnetic interference problems in the mine application of the frequency converter in the second coal mine of Selian and put forward several solutions. However, there are a few research studies on the electromagnetic disturbance characteristics of high-power frequency conversion equipment in coal mine.

In the limited space underground in the coal mine, there are a collection of power instruments such as ventilators, shearers, road headers, conveyors, hoists, and control instruments such as protection, control, and communication. It is a typical environment combining power instruments and control instruments [10, 11]. Control instruments work in a complex electromagnetic environment. In order to ensure the normal operation of coal mine control instruments and avoid the influence of electromagnetic interference, it is necessary to test and quantitatively analyze the electromagnetic interference sources in the environment.

The statistical characteristics of secondary system disturbance voltage under impulse current are analyzed in [12]. From [13], the distribution characteristics of electromagnetic disturbance in the near field of IGBT module of converter valve are statistically analyzed. It is difficult to predict and analyze the electromagnetic environment by digital simulation. Therefore, it is a better choice to analyze the electromagnetic environment in coal mines through statistical analysis of measured data $[14,15]$. This paper refers to the statistical method of electromagnetic disturbance data in substations and analyzes the electromagnetic disturbance caused by many high-voltage and high-power equipment in coal mines.

The electromagnetic disturbance data measured on site are limited, the sample size is small, and the data characteristics are dispersive [16]. Although the fact shows that a large number of observation data are subject to normal distribution, it is necessary to test the normality of the existing data $[17,18]$. In this paper, the Shapiro-Wilk test is used to test the normal distribution of small sample data, and a representative value of dominant frequency is obtained by using $80 \% / 80 \%$ rule. This paper uses these two methods to complete statistical analysis.

\section{Measurement of Electromagnetic Disturbance in Coal Mine}

The background of this test is in a mine affiliated to Jizhong Energy Group Company; it was discovered that the $\mathrm{CH}_{4}$ sensor installed about $1 \mathrm{~m}$ away from the local fan was often subject to electromagnetic disturbance, such as abnormal number, false alarm, crash, and restart. Therefore, the electromagnetic environment near the fan is tested. The sensor cable is about $10 \mathrm{~cm}$ away from the converter power cable, so we tested the disturbance at $10 \mathrm{~cm}$ near the converter power cable. And there may be other control equipment within $3 \mathrm{~m}$ around the converter, so we also chose $3 \mathrm{~m}$ test distance.
2.1. Test Instrument. Because there are flammable and explosive gases in coal mines, the field test conditions and equipment requirements are high. According to Coal Mine Safety Regulations, the power supply system of coal mine must meet the requirements of safe production, and it is not allowed to open the explosion proof shell of the equipment and destroy the explosion proof grade of the equipment. Moreover, it is inconvenient to get electricity underground, and the distance between each area is far. Therefore, the test instrument must be safe, light, and battery-powered and can save the measured data in real time [11]. In addition, the electromagnetic disturbance of mine mechanical and electrical equipment belongs to broadband disturbance with wide spectrum range, and the selected measurement instruments should be able to cover the whole radiation frequency band $[19,20]$. Taking into account the test requirements and the range of the spectrum of radiation disturbance, the measuring instrument adopts a Keysight spectrum analyzer N9342C, as shown in Figures 1 and 2 ; the antenna adopts $\mathrm{R} \&$ $\mathrm{S}^{\circledR} \mathrm{HE} 300$.

The tested equipment is a mine fan variable frequency speed regulating device, named ZJT-75, as shown in Figure 3 . The power of variable frequency speed regulating device is $75 \mathrm{~kW}$, the rated voltage is $660 \mathrm{~V}$, and the converter controlling fan power is $15 \mathrm{~kW}$. The converter has the function of online control, which can adjust the voltage and frequency of the motor working power supply according to the load change so as to achieve the required torque.

In the past, coal mines mostly adopted press in ventilation with fans, and the constant speed operation of fans often caused the phenomenon of "one wind blowing" $\mathrm{CH}_{4}$ discharge, which was easy to create $\mathrm{CH}_{4}$ accidents [21]. Applying ZJT series of mine frequency converter to fan control can effectively solve the discharge of $\mathrm{CH}_{4}$ in the process of underground roadway excavation and eliminate the hidden trouble of $\mathrm{CH}_{4}$ explosion caused by "one wind blowing" fundamentally [22].

2.2. Field Testing. In order to ensure the safe production of coal mines, prevent $\mathrm{CH}_{4}$ accumulation in the heading face, and ensure the stability and reliability of the ventilation system, the heading work is generally designed with subsystems such as dual fans, dual power supplies, automatic switching, variable frequency speed regulating device, and safety monitoring system. The safety monitoring system and $\mathrm{CH}_{4}$ sensor are arranged near the fans, and the local ventilation system is arranged as shown in Figure 4. After installing the fan variable frequency speed regulating device, the air volume can be automatically adjusted according to the $\mathrm{CH}_{4}$ content to achieve the purpose of rapid $\mathrm{CH}_{4}$ discharge. However, the application of variable frequency speed regulating device here also brings some electromagnetic disturbance, which may affect the $\mathrm{CH}_{4}$ sensor in the nearby safety monitoring system. Therefore, the electromagnetic environment near the variable frequency speed regulating device of local fan is tested. 


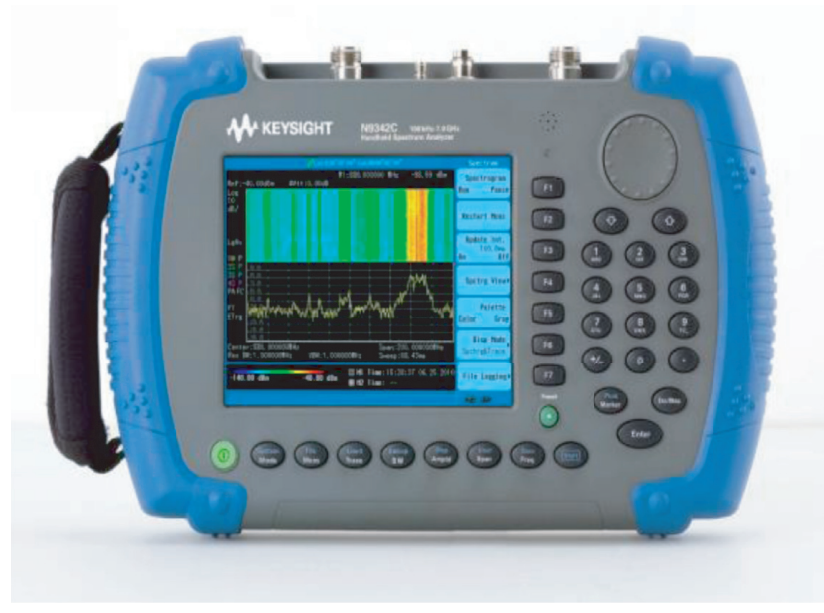

FIGURE 1: Spectrum analyzer boot chart.

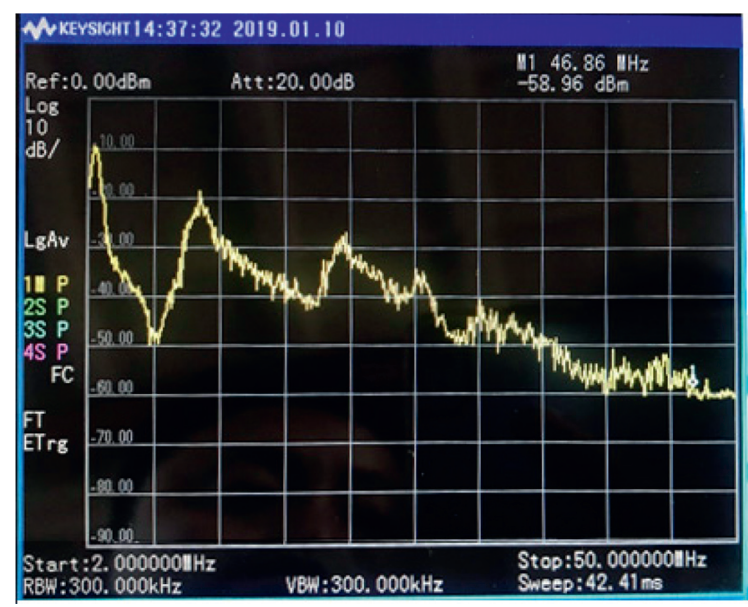

FIgURE 2: Spectrum analyzer measurement data map.

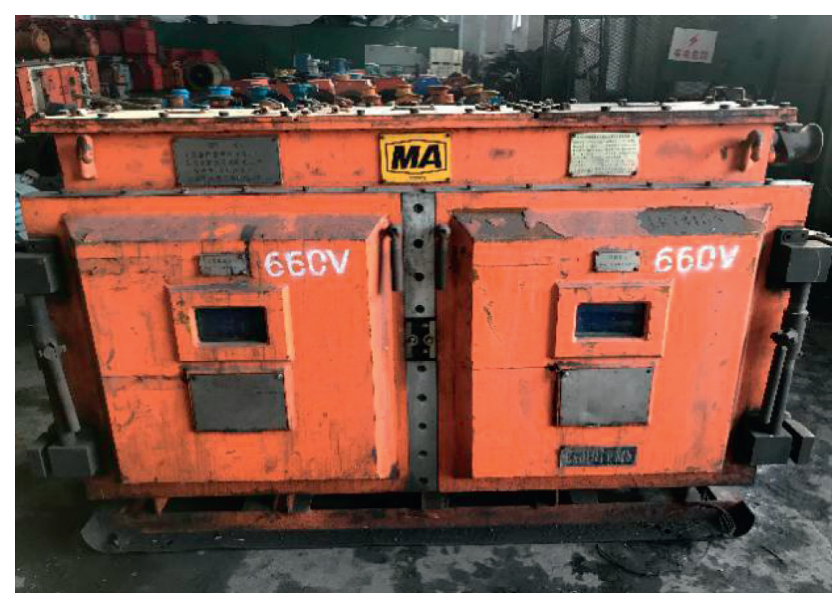

Figure 3: The variable frequency speed regulating device.

The output frequency range of the fan variable frequency speed regulating device used in this test is $0.5-60 \mathrm{~Hz}$. In order to eliminate the influence of different frequency on the measured data, the test output frequency is $20 \mathrm{~Hz}$ and $35 \mathrm{~Hz}$, respectively. We measured at several locations around the

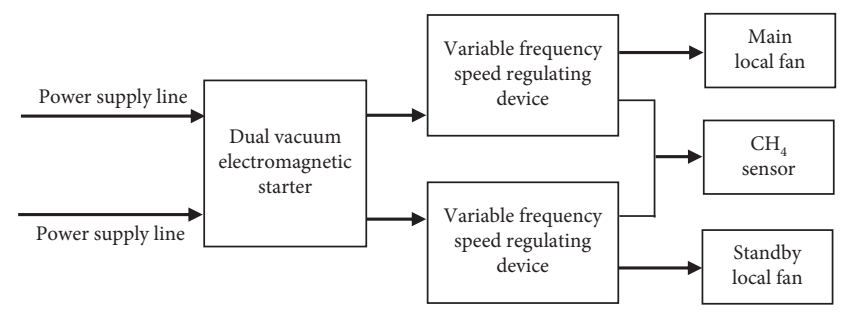

Figure 4: Layout plan for local ventilation system.

converter. Considering that the output cable of the variable frequency speed regulating device is parallel to the power supply and signal cables of the $\mathrm{CH}_{4}$ sensor, after comparison and analysis, the test results at four locations were selected, including the three near field locations of the converter power input, output, and fan cable input and the location at a distance of $3 \mathrm{~m}$, as shown in Figure 5; these locations can more typically reflect the interference situation of the converter.

\section{Characteristics of Electromagnetic Disturbance Data}

All kinds of electromagnetic disturbance can be obtained by measurement in coal mine. The electromagnetic disturbance of different equipment in different positions has different characteristics. The frequency domain characteristics of disturbance can provide a reference for the design of shielding and filtering of control instruments. In addition, the frequency domain characteristics of disturbance are also an important basis for the design of immunity test. Therefore, summarizing the frequency domain characteristics of electromagnetic disturbance is an important step to scientifically evaluate the electromagnetic environment in coal mines and guide the antidisturbance design of control instruments.

\subsection{Definition of Characteristic Parameters of Electromagnetic} Disturbance. Basic parameters of electromagnetic disturbance frequency domain include disturbance upper limit frequency, bandwidth, and dominant frequency. In this paper, the frequency domain analysis of downhole transient electromagnetic disturbance test data mainly refers to the dominant frequency (DF). It is defined as follows.

In the range of disturbance frequency band, among several obviously prominent frequency groups, the maximum point with the largest amplitude is selected as the dominant frequency [17].

3.2. Basic Analysis of Electromagnetic Disturbance Characteristics. The test data are shown in the spectrum, the abscissa is the frequency $(\mathrm{MHz})$, and the ordinate is the electric field $(\mathrm{dB} \mu \mathrm{V} / \mathrm{m})$. The following four groups of data were analyzed.

Figure 6 shows the frequency spectrum of electromagnetic disturbance $10 \mathrm{~cm}$ away from the output power cable of converter. The test frequency range is $1-50 \mathrm{MHz}$. According 


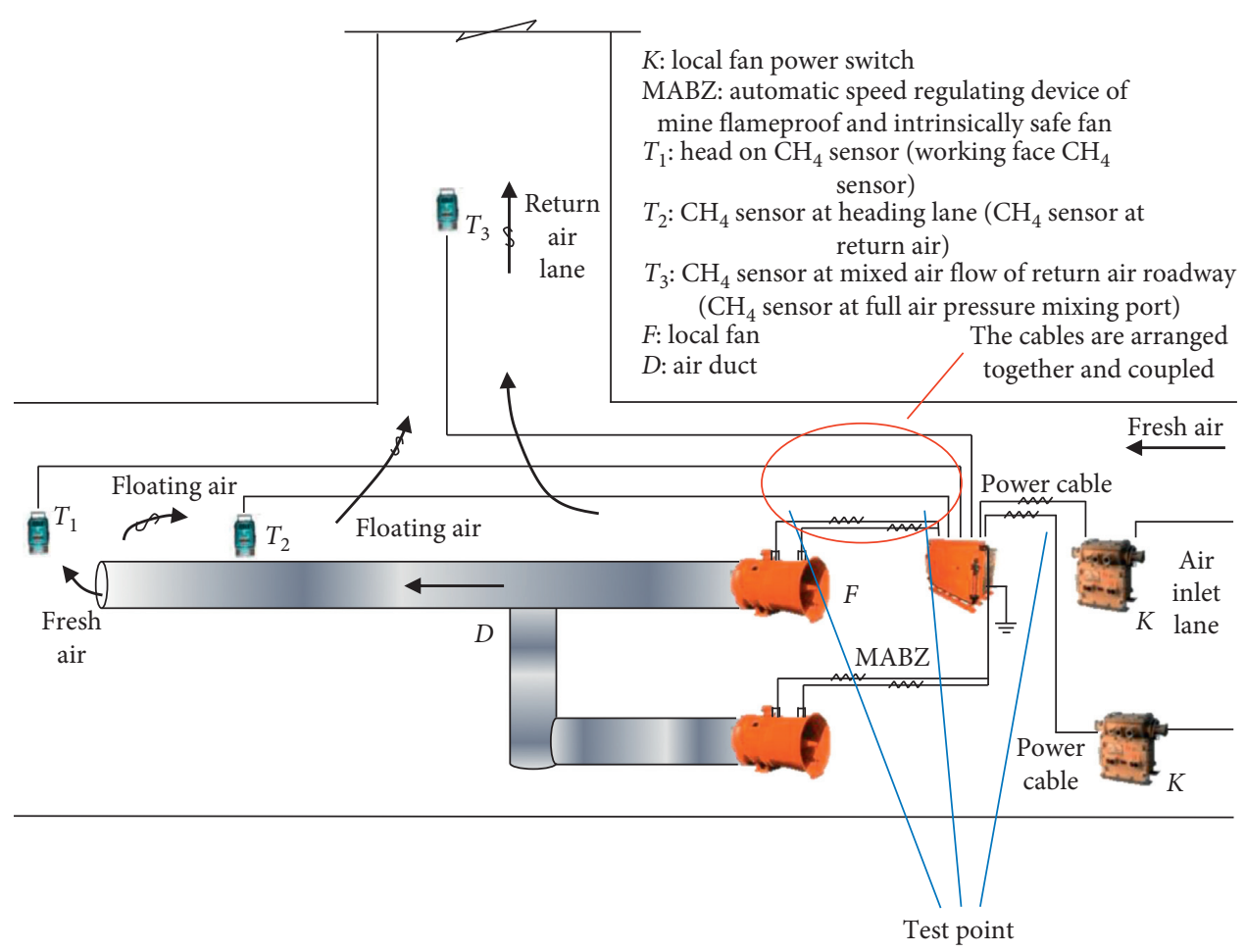

FIGURE 5: Installation of speed control device.

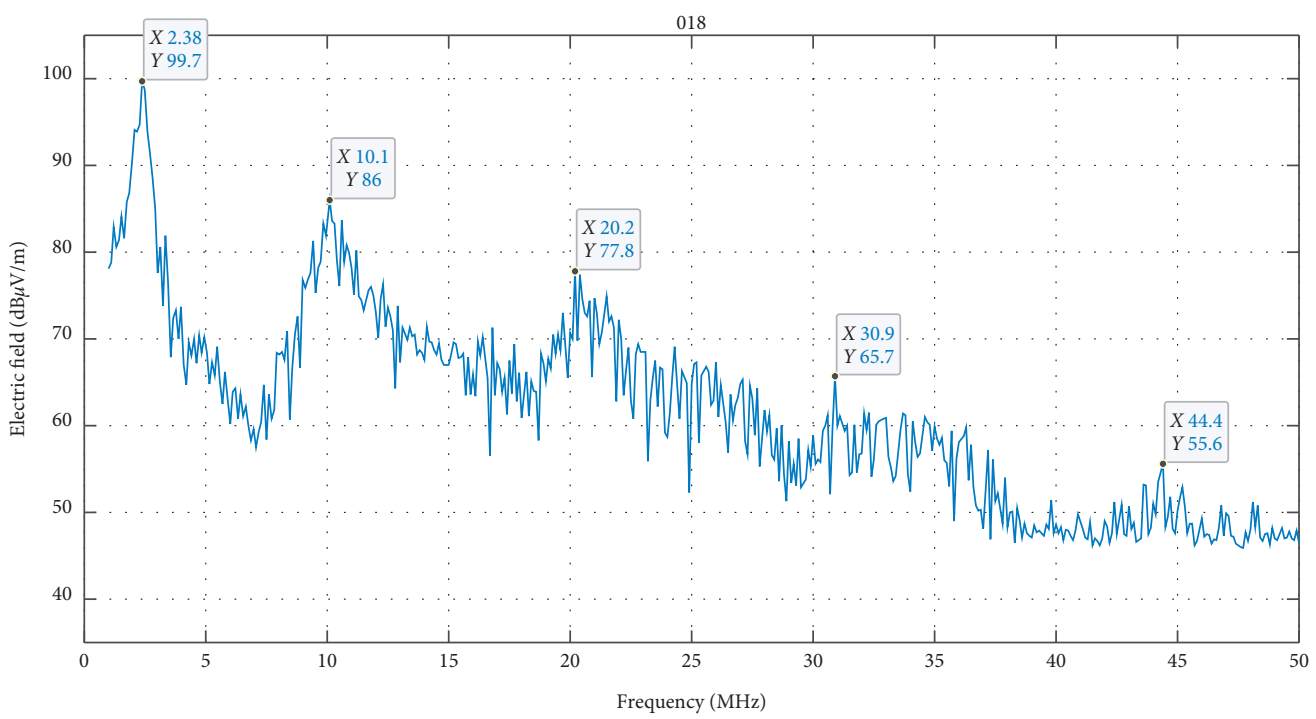

FIGURE 6: Frequency spectrum of electromagnetic disturbance $10 \mathrm{~cm}$ away from the output power cable of converter.

to the definition of the dominant frequency, the main frequency distribution of the frequency spectrum of electromagnetic disturbance is $2.38 \mathrm{MHz}, 10.10 \mathrm{MHz}, 20.20 \mathrm{MHz}$, $30.90 \mathrm{MHz}$, and $44.40 \mathrm{MHz}$. The disturbance near $2.38 \mathrm{MHz}$ is the largest, and the amplitude is $99.7 \mathrm{~dB} \mu \mathrm{V} / \mathrm{m}$.

Figure 7 shows the frequency spectrum of electromagnetic disturbance $10 \mathrm{~cm}$ away from the input power cable of converter. The test frequency range is $1-50 \mathrm{MHz}$. Further analysis shows that the main frequency distribution of the frequency spectrum of electromagnetic disturbance is 2.28 MHz, $\quad 11.33 \mathrm{MHz}, \quad 14.85 \mathrm{MHz}, \quad 17.08 \mathrm{MHz}$, and
26.88 MHz. The disturbance near $2.28 \mathrm{MHz}$ is the largest, and the amplitude is $74.47 \mathrm{~dB} \mu \mathrm{V} / \mathrm{m}$.

Figure 8 shows the frequency spectrum of electromagnetic disturbance tested at $3 \mathrm{~m}$ from the front of the converter. The test frequency range is $0.2-20 \mathrm{MHz}$. The main frequency distribution of the frequency spectrum of electromagnetic disturbance is $0.58 \mathrm{MHz}, 2.44 \mathrm{MHz}$, and $4.86 \mathrm{MHz}$. The disturbance near $0.58 \mathrm{MHz}$ is the largest, and the amplitude is $60.85 \mathrm{~dB} \mu \mathrm{V} / \mathrm{m}$.

Figure 9 shows the frequency spectrum of electromagnetic disturbance at $10 \mathrm{~cm}$ near the motor side cable 


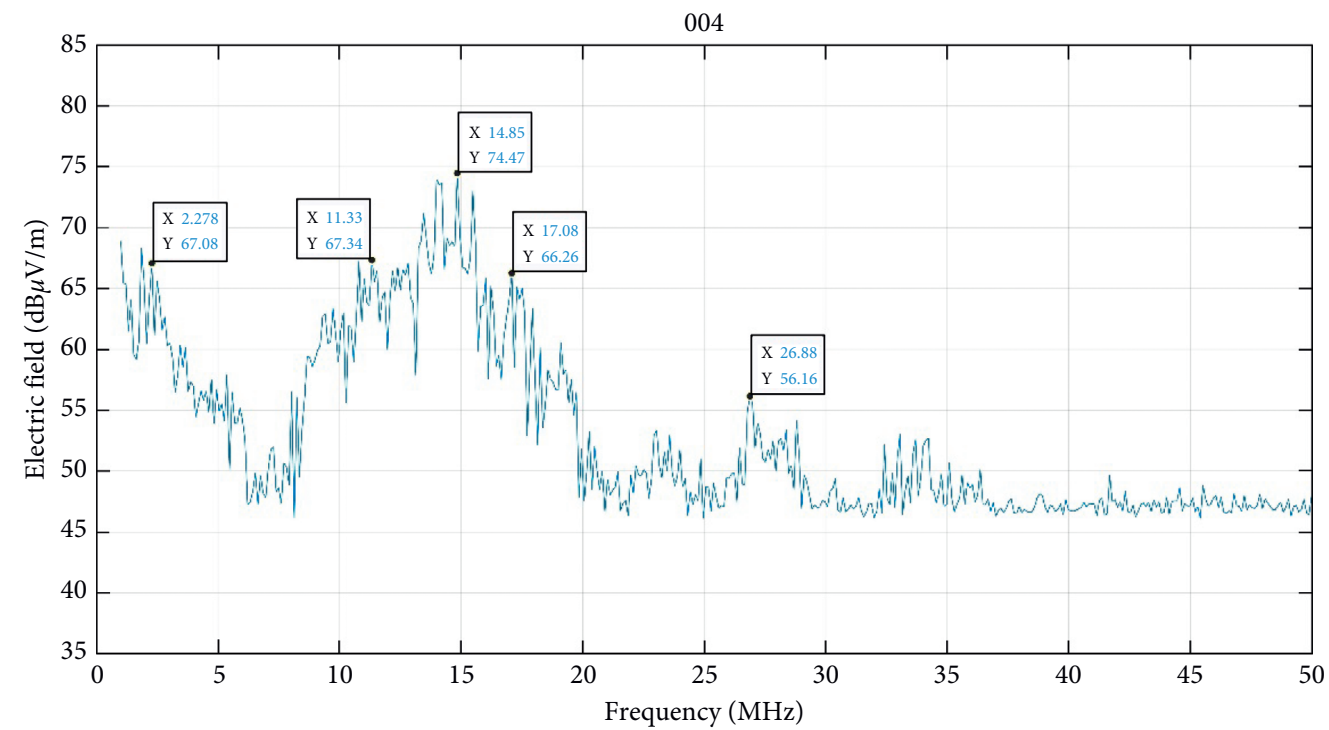

FIgURE 7: Frequency spectrum of electromagnetic disturbance $10 \mathrm{~cm}$ away from the input power cable of converter.

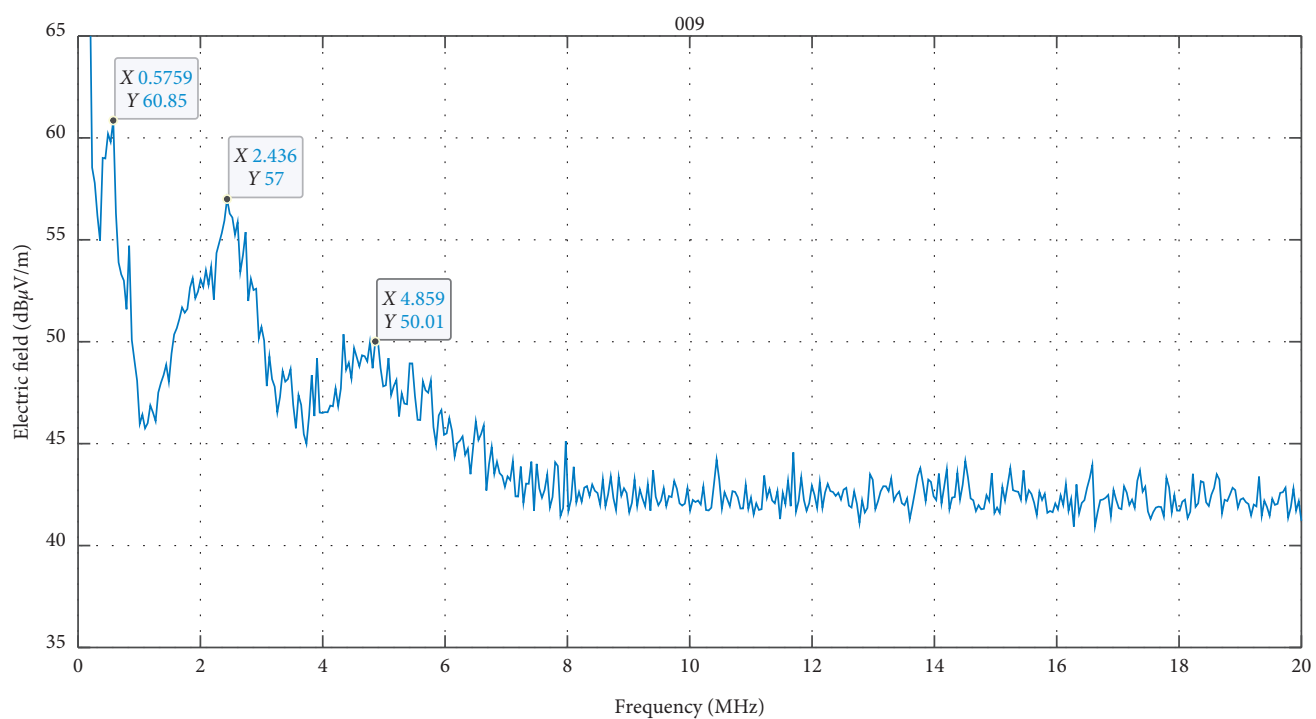

FIGURE 8: Frequency spectrum of electromagnetic disturbance tested at $3 \mathrm{~m}$ from the front of the converter.

on the converter connected motor cable. The test frequency range is $1-50 \mathrm{MHz}$. Further analysis shows that the main frequency distribution of the frequency spectrum of electromagnetic disturbance is $2.39 \mathrm{MHz}$, 9.63 MHz, $19.90 \mathrm{MHz}, 26.70 \mathrm{MHz}$, and $33.00 \mathrm{MHz}$. The disturbance near $2.39 \mathrm{MHz}$ is the largest, and the amplitude is $98.09 \mathrm{~dB} \mu \mathrm{V} / \mathrm{m}$.

The interference produced by the converter is mainly at the output end of the power supply, and the interference attenuates with the distance. The farther away from the converter, the smaller the interference. The power cable output from the converter to the motor is a strong interference source, so it should be far away from this interference source as far as possible when the sensor is arranged. The observed frequency characteristics of the converter interference reach obvious peaks at certain frequency points, and the signal transmission protocol of the sensor should try to avoid these frequencies to prevent cofrequency interference.

3.3. Statistical Test of Characteristic Parameters of Electromagnetic Disturbance. The disturbance data has a certain randomness. Therefore, the randomness of the data makes the disturbance signal measured single time not be used as the basis for evaluating the disturbance level of the whole system. It is necessary to use statistical methods to obtain the statistical characteristics and then to comprehensively and objectively predict and evaluate the disturbance level of the whole system. But due to the small sample characteristics of the data, it is difficult to determine the distribution of the population. We need to test the normality of the data first and then estimate the parameters based on the characteristics of the normal distribution. 


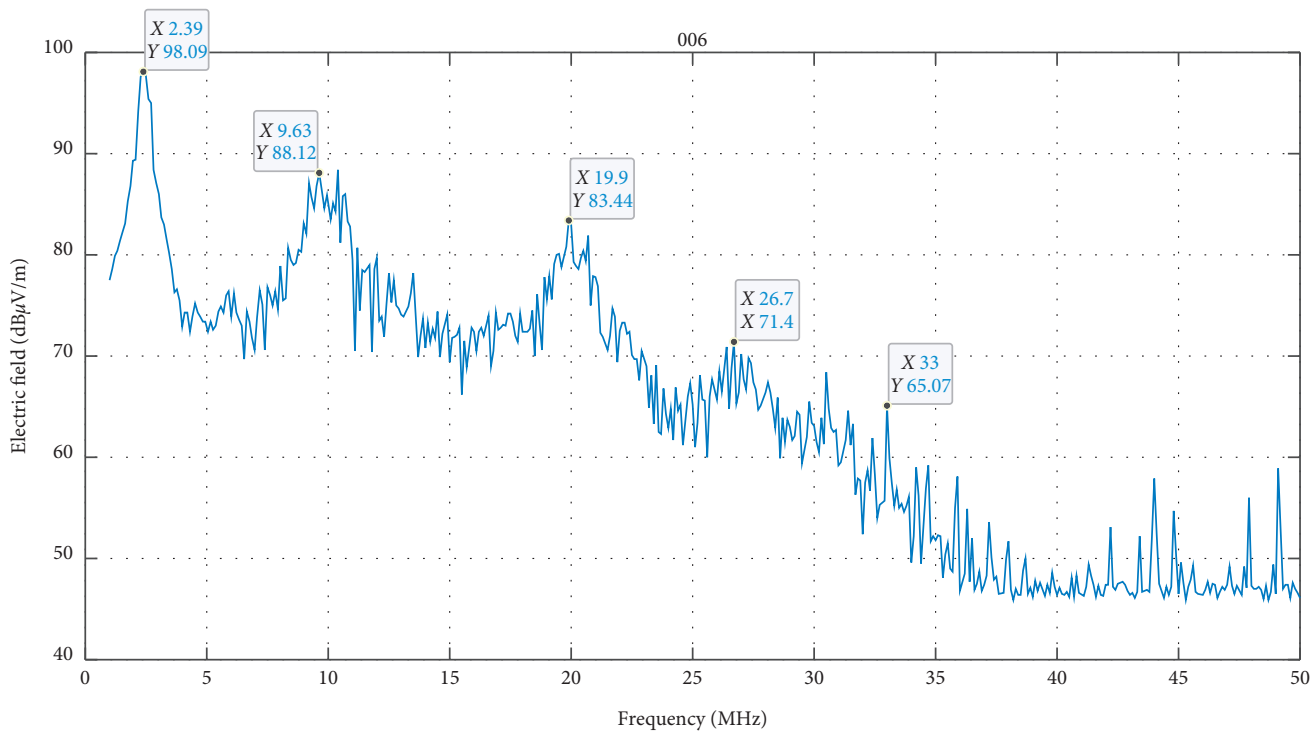

FIGURE 9: Frequency spectrum of electromagnetic disturbance tested at $10 \mathrm{~cm}$ near the motor side cable on the converter connected motor cable.

3.3.1. Shapiro-Wilk Test. The Shapiro-Wilk test was proposed by S. S. Shapiro and M. B. Wilk in 1965. When the sample size is $3 \leq n \leq 30$, the Shapiro-Wilk test of normality assumption is effective [23].

Implementation steps for the Shapiro-Wilk test are as follows:

Step 1: arrange $n$ observations in small to large order $x_{(1)} \leq x_{(2)} \leq \cdots \leq x_{(n)}$.

Step 2: follow the following equation:

$$
W=\frac{\left\{\sum_{k=1}^{l} \alpha_{k}(W)\left[x_{(n+1-k)}-x_{(k)}\right]\right\}^{2}}{\sum_{k=1}^{n}\left[x_{(k)}-\bar{x}\right]^{2}} .
$$

Calculate the statistical value $W$. Where $n$ is even, $l=(n / 2)$, and when $n$ is odd, $l=(n-1 / 2) ; \bar{x}$ represents the sample mean number. The value corresponding to $\alpha_{k}(W)$ can be obtained from coefficient table [24].

Step 3: according to $p$ and $n$, check table ( $p$ quantile $Z_{p}$ table of statistics $W$ ) [24] to get $Z_{P}$ of $W$.

Step 4: make a judgment; if $W<Z_{p}$, then reject $H_{0}$; otherwise do not reject $H_{0}\left(H_{0}\right.$ : the population obeys normal distribution).

3.3.2. $80 \% / 80 \%$ Rule. In order to describe the characteristics of transient electromagnetic disturbance scientifically, statistical analysis method must be used. The $80 \% / 80 \%$ rule is a sampling inspection rule for disturbance level measurement recommended by CISPR.

Sampling inspection can be divided into two categories: sampling by variables and sampling by attributes. Sampling by variables is to test and calculate the characteristic values in the sample and then compare them with the qualified number specified in the judgment criterion to determine whether the batch of products is qualified. Sampling by attributes is only to give " 0 " or " 1 " to the samples, depending on whether the number of samples is 0 (or 1) to determine whether the product is qualified. The $80 \% / 80 \%$ rule is based on simple random sampling and measurement sampling. The emission level (immunity level) is a continuous random variable and conforms to the normal distribution.

CISPR 22 specifies a method for making the statistical calculations, one which assumes that the regulated parameter electric field in $\mathrm{dB} \mu \mathrm{V} / \mathrm{m}$ is from a Gaussian, or normally distributed, population, and applies the noncentral $t$ distribution to establish the appropriate confidence [25]. In this paper, the criterion is used in frequency domain analysis of transient electromagnetic disturbance data. The purpose is to define the limit value $L$ as the representative value of a group of data and to provide a basis for formulating the immunity test standard of secondary equipment in the future.

The sample mean $\bar{x}_{n}$ is defined as

$$
\bar{x}_{n}=\frac{1}{n} \sum_{i=1}^{n} x_{i} \text {. }
$$

The sample standard deviation $S_{n}$ is defined as

$$
S_{n}=\sqrt{\frac{\sum_{i=1}^{n}\left(x_{i}-\bar{x}\right)^{2}}{n-1}} \text {. }
$$

The expression of $80 \% / 80 \%$ rule [26] is

$$
\bar{x}_{n}+k S_{n} \leq L,
$$

where $\bar{x}_{n}$ is the mean of the amplitudes of $n$ samples in the test; $L$ is the regulatory limit; $S_{n}$ is determined by equation (3); $x_{i}$ is the amplitude of the $i$ sample; and $k$ is the factor, dependent on the number of samples, which yields $80 \%$ confidence; and the $k$ value is shown in Table 1 .

Based on the statistical analysis, we define the $80 \% / 80 \%$ rule used in this paper: at least $80 \%$ of the test data are met 
TABLE 1: Value of $k$.

\begin{tabular}{ccccccccccccc}
\hline$n$ & 3 & 4 & 5 & 6 & 7 & 8 & 9 & 10 & 11 & 12 & 15 & 20 \\
\hline$k$ & 2.04 & 1.69 & 1.52 & 1.42 & 1.35 & 1.30 & 1.27 & 1.24 & 1.21 & 1.20 & 1.17 & 1.12 \\
\hline
\end{tabular}

TABLe 2: $35 \mathrm{~Hz}$ basic parameter analysis.

\begin{tabular}{|c|c|c|c|c|}
\hline Location & $\begin{array}{c}\text { Data } \\
\text { number }\end{array}$ & $\begin{array}{l}\text { Frequency band range } \\
(\mathrm{MHz})\end{array}$ & $\begin{array}{l}\text { Dominant frequency } \\
(\mathrm{MHz})\end{array}$ & $\begin{array}{l}\text { Corresponding amplitude } \\
(\mathrm{dB} \mu \mathrm{V} / \mathrm{m})\end{array}$ \\
\hline \multirow{10}{*}{ Near the output power cable of converter } & \multirow{5}{*}{018} & \multirow{5}{*}{$0-50$} & 2.38 & 99.70 \\
\hline & & & 10.10 & 86.00 \\
\hline & & & 20.20 & 77.80 \\
\hline & & & 30.90 & 65.70 \\
\hline & & & 44.40 & 55.60 \\
\hline & \multirow{3}{*}{023} & \multirow{3}{*}{$0-20$} & 2.31 & 94.30 \\
\hline & & & 10.30 & 80.70 \\
\hline & & & 16.20 & 81.50 \\
\hline & \multirow[b]{2}{*}{027} & \multirow[b]{2}{*}{$20-200$} & 32.50 & 82.30 \\
\hline & & & 42.70 & 75.10 \\
\hline \multirow{7}{*}{ Near the input power cable of converter } & \multirow{4}{*}{022} & \multirow{4}{*}{$0-20$} & 2.22 & 85.56 \\
\hline & & & 11.30 & 78.82 \\
\hline & & & 14.33 & 83.77 \\
\hline & & & 17.71 & 77.36 \\
\hline & \multirow{3}{*}{026} & \multirow{3}{*}{$20-200$} & 27.43 & 84.46 \\
\hline & & & 33.70 & 74.64 \\
\hline & & & 44.65 & 65.38 \\
\hline \multirow{11}{*}{$\begin{array}{l}\text { Output connecting motor cable close to } \\
\text { the motor side }\end{array}$} & \multirow{4}{*}{020} & \multirow{4}{*}{$0-50$} & 2.39 & 95.16 \\
\hline & & & 9.74 & 85.38 \\
\hline & & & 20.17 & 83.42 \\
\hline & & & 33.28 & 65.87 \\
\hline & \multirow{3}{*}{025} & \multirow{3}{*}{$0-20$} & 2.48 & 89.22 \\
\hline & & & 9.70 & 75.24 \\
\hline & & & 13.90 & 80.08 \\
\hline & \multirow{4}{*}{028} & \multirow{4}{*}{$20-200$} & 20.39 & 76.48 \\
\hline & & & 24.70 & 75.44 \\
\hline & & & 34.48 & 74.14 \\
\hline & & & 41.91 & 68.76 \\
\hline
\end{tabular}

(less than or equal to) the specified limit with at least $80 \%$ confidence.

\section{Testing and Analysis}

The frequency spectrum analyzer N9342C is used to the four test points of the general converter. The output frequency of the converter is $35 \mathrm{~Hz}$ and $20 \mathrm{~Hz}$. The spectrum characteristics of electromagnetic disturbance under two groups of working frequencies are obtained, and the frequency domain basic analysis is carried out on the measurement data of the converter of the fan in the coal mine. The data are listed in Tables 2 and 3.

According to the analysis of the main frequency points of the image in this paper, five groups of data are obtained, which are arranged in order from small to large, followed by

Group 1: 2.22, 2.28, 2.28, 2.31, 2.38, 2.39, 2.39, 2.40, $2.44,2.48,2.48,2.73$

Group 2: 9.63, 9.70, 9.74, 10.10, 10.16, 10.27, 10.30, $10.49,11.30,11.33$

Group 3: 19.90, 20.17, 20.20, 20.39, 20.71, 21.14, 21.96
Group 4: 30.90, 31.07, 32.50, 33.00, 33.28, 33.70, 34.48, 35.26

Group 5: 41.00, 41.91, 41.91, 42.70, 42.97, 44.40, 44.65

The five groups of data were tested by Shapiro-Wilk test, and the statistical values $W$ were $0.869,0.801,0.982,0.950$, and 0.931. Take group 1 data as an example; if the test level $\alpha=0.05$, when $n=12, W_{0.05}=0.859$, because $0.869>0.859$, the original hypothesis is not rejected. The data of groups 1 , 3,4 , and 5 did not reject the original hypothesis at test level $\alpha=0.05$, and the data of group 2 did not reject the original hypothesis at test level $\alpha=0.01$. Therefore, the above five groups of data are subject to normal distribution; we can apply the $80 \% / 80 \%$ rule for further statistical analysis of the data. Taking the first group of dominant frequency data as an example, $n=12, k=1.20$, and $\mathrm{DF}_{1}=2.56 \mathrm{MHz}$. Similarly, other dominant frequencies are $11.05 \mathrm{MHz}, 21.60 \mathrm{MHz}$, $35.00 \mathrm{MHz}$, and $44.61 \mathrm{MHz}$.

The above data can show that, even if the test location is different, the working frequency of the converter is different, and there is generally large amplitude disturbance near $2.56 \mathrm{MHz}, \quad 11.05 \mathrm{MHz}, \quad 21.60 \mathrm{MHz}, \quad 35.00 \mathrm{MHz}$, and 
TABLE 3: $20 \mathrm{~Hz}$ basic parameter analysis.

\begin{tabular}{|c|c|c|c|c|}
\hline Location & $\begin{array}{c}\text { Data } \\
\text { number }\end{array}$ & $\begin{array}{l}\text { Frequency band range } \\
(\mathrm{MHz})\end{array}$ & $\begin{array}{c}\text { Dominant frequency } \\
(\mathrm{MHz})\end{array}$ & $\begin{array}{c}\text { Corresponding amplitude } \\
\qquad(\mathrm{dB} \mu \mathrm{V} / \mathrm{m})\end{array}$ \\
\hline \multirow{15}{*}{ Near the output power cable of converter } & \multirow{3}{*}{008} & \multirow{3}{*}{$0-20$} & 2.40 & 92.10 \\
\hline & & & 10.27 & 74.15 \\
\hline & & & 14.98 & 80.68 \\
\hline & \multirow{6}{*}{007} & \multirow{5}{*}{$0-50$} & 2.28 & 96.39 \\
\hline & & & 10.16 & 85.19 \\
\hline & & & 14.74 & 86.76 \\
\hline & & & 20.71 & 76.89 \\
\hline & & & 42.97 & 69.87 \\
\hline & & \multirow{5}{*}{$0-50$} & 2.73 & 97.50 \\
\hline & \multirow{4}{*}{0032} & & 10.49 & 88.31 \\
\hline & & & 21.14 & 80.25 \\
\hline & & & 31.07 & 66.54 \\
\hline & & & 41.00 & 56.25 \\
\hline & \multirow{2}{*}{013} & \multirow{2}{*}{$20-200$} & 21.96 & 79.51 \\
\hline & & & 41.91 & 70.61 \\
\hline \multirow{7}{*}{ Near the input power cable of converter } & \multirow{5}{*}{004} & \multirow{5}{*}{$0-50$} & 2.28 & 67.08 \\
\hline & & & 11.33 & 67.34 \\
\hline & & & 14.85 & 74.47 \\
\hline & & & 17.08 & 66.26 \\
\hline & & & 26.88 & 56.16 \\
\hline & \multirow{2}{*}{012} & \multirow{2}{*}{$20-200$} & 27.04 & 73.61 \\
\hline & & & 35.26 & 64.09 \\
\hline \multirow{5}{*}{$3 \mathrm{~m}$ from the converter } & \multirow{3}{*}{009} & \multirow{3}{*}{$0-20$} & 0.58 & 60.85 \\
\hline & & & 2.44 & 57.00 \\
\hline & & & 4.86 & 50.01 \\
\hline & \multirow{2}{*}{010} & \multirow{2}{*}{$0-20$} & 2.48 & 51.03 \\
\hline & & & 4.77 & 45.11 \\
\hline \multirow{5}{*}{$\begin{array}{l}\text { Output connecting motor cable close to } \\
\text { the motor side }\end{array}$} & \multirow{5}{*}{006} & \multirow{5}{*}{$0-50$} & 2.39 & 98.09 \\
\hline & & & 9.63 & 88.12 \\
\hline & & & 19.90 & 83.44 \\
\hline & & & 26.70 & 71.40 \\
\hline & & & 33.00 & 65.07 \\
\hline
\end{tabular}

44.61 MHz. These five groups of frequencies are the common frequencies that the converter may produce electromagnetic disturbance (electric field in $\mathrm{dB} \mu \mathrm{V} / \mathrm{m}$ ). The $\mathrm{CH}_{4}$ sensor and other sensors work near these five dominant frequencies, which may affect the normal operation of the sensor and cause false alarm.

\section{Conclusion}

In this paper, a field test was conducted on a fan converter of a widely used model in the mine, and the electromagnetic disturbance data and frequency spectrum obtained were observed and analyzed statistically. Based on the small sample data, the Shapiro-Wilk test method is selected in the statistical method. After calculation, the dominant frequency samples in this paper conform to the normal distribution, and then the $80 \% /$ $80 \%$ rule is used to obtain its statistical characteristics. It can be concluded that the five frequencies of $2.56 \mathrm{MHz}$, 11.05 MHz, 21.60 MHz, 35.00 MHz, and $44.61 \mathrm{MHz}$ are the common frequencies of electromagnetic disturbance (electric field in $\mathrm{dB} \mu \mathrm{V} / \mathrm{m}$ ). Even if the test location is different and the frequency of the converter is different, there is still interference near the common frequency.
The $\mathrm{CH}_{4}$ sensor and other sensors work near these five dominant frequencies, which may affect the normal operation of the sensor and cause false alarm. According to the electromagnetic interference test results of the converter, the sensor should be arranged as far away from the converter as possible; pay attention to the power signal wiring of the sensor, and keep away from the power output cable of the converter, especially avoiding long distance parallel wiring; if the sensor near the converter is unstable, try to change the signal transmission frequency of the sensor.

There are further plans to establish an equivalent model and simulate the converter, study the mechanism of electromagnetic disturbance of converters, and affect factors and suppression measures. It provides reference significance for the design and layout of mine converter and secondary equipment in coal mines.

\section{Data Availability}

The data used to support the findings of this study are included within the article and are available from the corresponding author upon request. The authors agree to make the data public. 


\section{Conflicts of Interest}

The authors declare that there are no conflicts of interest regarding the publication of this study.

\section{Acknowledgments}

This research was funded by China Coal Technology Engineering Group, grant number 2020-ZD005.

\section{References}

[1] S. Zhang, "Energy consumption status analysis and energy saving technology development tendency in coal mine," Coal Science and Technology, vol. 37, no. 5, pp. 83-85, 2009.

[2] Z. Xin, X. Zhang, T. Liu, H. Chen, Z. Zhang, and K. Su, "Research on electromagnetic interference characteristics and electromagnetic compatibility standard of intelligent equipment," Coal Science and Technology, vol. 48, no. 7, pp. 255261, 2020.

[3] C. Xing, "Analysis and verification methods of abnormal data of coal mine safety monitoring system," Industry and Mine Automation, vol. 43, no. 6, pp. 14-17, 2017.

[4] D. Feng, M. Lu, J. Lan, and L. Sun, "Research on switching operation transient electromagnetic environment of substations in a coal mine," IET Generation, Transmission \& Distribution, vol. 10, no. 13, pp. 3322-3329, 2016.

[5] F. Ma, "Wavelet analysis applied in measurement of coal mining underground EMI and design of filter," in Proceedings of the 2008 IEEE International Conference on Automation and Logistics, pp. 2565-3064, Qingdao, China, September 2008.

[6] D. Hill and J. Wait, "The impedance of dipoles in a circular tunnel with an axial conductor," IEEE Transactions on Geoscience Electronics, vol. 16, no. 2, pp. 118-126, 1978.

[7] D. A. Hill and J. R. Wait, "Electromagnetic theory of the loosely braided coaxial cable: part II--numerical results," IEEE Transactions on Microwave Theory and Techniques, vol. 28, no. 4, pp. 326-331, 1980.

[8] H. Chen, "Electromagnetic disturbances in fully-mechanized mining tunnels," Ph.D. thesis, China University of Mining \& Technology, Beijing, China, , 2012.

[9] M. Wang, "Problems and solutions of converter application in coal mine," China Plant Engineering, no. 1, pp. 63-64, 2017.

[10] J. Sun, J. Ren, D. Feng, and Z. Zheng, "The measurement on the electromagnetic radiation property of electrical equipment at transformer station in the underground coal mine," Journal of China Coal Society, vol. 35, no. 5, pp. 861-864, 2010.

[11] H. Chen, Z. Tian, K. Lu, Z. Liang, and Z. Wang, "Radiated electromagnetic disturbance for the water pump motor in underground coal mines," Coal Science and Technology, vol. 47, no. 9, pp. 214-218, 2019.

[12] C. Li, W. Zhang, J. Ji, Z. Zhang, and W. Shi, "Research on statistical characteristics of disturbance voltage of secondary system under impulse current and its consistency with immunity test," Power System Technology, vol. 14, no. 2, pp. 1-9, 2010.

[13] Y. Hu, W. Zhang, L. Zhang, L. Qi, and W. Kang, "The research on IGBT near-field electromagnetic disturbance characteristic of UPFC converter valves," Electrical Engineering, vol. 16, no. 9, pp. 1-6, 2015.

[14] Y. Wang, J. Zou, and M. Liao, "EMC prediction and analysis in power system based on data mining technology," High Voltage Apparatus, vol. 43, no. 3, pp. 183-185, 2007.
[15] H. Lu, J. Wei, and T. Huang, "EMC prediction of missile system based on the data digging technology. Shipboard electronic countermeasure," Shipboard Electronic Countermeasure, vol. 32, no. 3, pp. 21-24, 2009.

[16] W. Zhang, F. Gao, and X. Cui, "Small sample statistics for transient electromagnetic disturbance characteristics of HVDC converter stations," Power System Technology, vol. 36, no. 5, pp. 11-15, 2012.

[17] J. Su, "Research on characteristic analysis and statistical method of electromagnetic disturbance," MA.-English. thesis, North China Electric Power University (Hebei), Beijing, China, 2007.

[18] W. Zhang and X. Cui, "Measurement and analysts of electromagnetic disturbances in substations and converter stations," Guangdong Power Transmission Technology, vol. 11, no. 1, pp. 1-9, 2009.

[19] J. Sun, Q. Cheng, and Z. Tian, "Study on electromagnetic radiated emission of PWM invert in coal mine," Journal of Taiyuan University of Technology, vol. 42, no. 5, pp. 528-530, 2011.

[20] H. Chen, Z. Tian, and K. Lu, "Radiated electromagnetic disturbance for the water pump motor in underground coal mines," Journal of Microwaves, vol. 32, no. 6, pp. 76-80, 2016.

[21] B. Yao, "Design and application of automatic speed regulating device for gas drainage in roadway," Shandong Coal Science and Technology, vol. 37, no. 10, pp. 121-122+125, 2019.

[22] H. Zhao, "New high-performance automatic gas-discharging device for heading face," Colliery Mechanical \& Electrical Technology, vol. 31, no. 3, pp. 7-9, 2010.

[23] F. Gao, "Study on statistical characteristic of electromagnetic disturbances and correlation with immunity waveform," MA.English. thesis, North China Electric Power University, Beijing, China, 2011.

[24] X. Liang, Statistical processing and interpretation of the data normality test, 2001.

[25] L. Kolb and IEEE, "Opportunities for improved 80\%/80\% statistical methods with CISPR 32," in Proceedings of the 2012 IEEE International Symposium on Electromagnetic Compatibility, pp. 457-461, Rome, Italy, September 2012.

[26] Specification for Radio Disturbance and Immunity Measuring Apparatus and Methods, IEC, Geneva, Switzerland, 2006. 